\title{
Investigation of the Quenching Properties of Selected Media on 6061 Aluminum Alloy
}

\author{
O. K. Abubakre*, U. P. Mamaki** and R. A Muriana* \\ *Department of Mechanical Engineering \\ Federal University of Technology, Minna \\ ** Waziri Umaru Polytechnic, \\ Birnin Kebbi \\ *Corresponding Author, contact: mraremu@yahoo.com
}

\begin{abstract}
Specimens of 6061 Aluminum alloy were prepared and quenched in water, sheanut oil and palm oil at temperature of $400^{\circ} \mathrm{C}, 450^{\circ} \mathrm{C}$ and $530^{\circ} \mathrm{C}$ to determine the effect of variation in temperature and quenching media on some mechanical properties and the microstructure of the alloy. Standard specimens from the rapidly quenched alloys were subject to various tests to determine their ultimate tensile strength, hardness and impact strength. The results showed that the specimen heat-treated to $530^{\circ} \mathrm{C}$ and quenched in water has the highest tensile strength of 109 $\mathrm{N} / \mathrm{mm}^{2}$ and yield strength of $70.89 \mathrm{~N} / \mathrm{mm}^{2}$. The specimen heated at $530^{\circ} \mathrm{C}$ and quenched in water gave the highest value of 35.50 in hardness (HRC). The toughness property of the alloy, as indicated by Charpy impact values, is better at $530^{\circ} \mathrm{C}$ for specimen quenched in sheanut oil and least impact strength is observed in specimen quenched in water at $400^{\circ} \mathrm{C}$.
\end{abstract}

\section{Key Words:}

\section{INTRODUCTION}

Heat treatment is an important operation in the final fabrication process of any engineering component. The objective of heat treatment however, is to make the metal better suited, structurally and physically, for some specific application [1]. Solution heat treatment of aluminum alloys allows the maximum concentration of a hardening solute to dissolve into solution. This procedure is typically carried out by heating the alloy to a temperature at which 
one single, solid phase exists. By doing so, the solute atoms that were originally part of a two phase solid solution dissolve into solution and create one single phase. Once the alloy has been heated to the recommended solutionizing temperature, it is quenched at a rapid rate such that the solute atoms do not have enough time to precipitate out of the solution. As a result of the quench, a super saturated solution now exists between solute and aluminum matrix [2-3].

The cooling rate associated with the quench can be controlled through the variation of quenching parameters such as bath temperature and degree of agitation. The variation of this parameter allows the heat transfer, the ability to increase or decrease the cooling rate to achieve certain mechanical properties as well as eliminate distortion and the possibility of cracking [4].

The primary objective of this work is to experimentally determine the effect sheanut oil and palm kernel oil on the mechanical properties of 6061 aluminum alloys. The properties of interest include: tensile strength, impact strength, hardness and the microstructural changes.

The results of tests conducted showed that the specimen heat-treated to $530^{\circ} \mathrm{C}$ and quenched in water has the highest tensile strength of $109 \mathrm{~N} / \mathrm{mm}^{2}$ and yield strength of $70.89 \mathrm{~N} / \mathrm{mm}^{2}$. The specimen heated at $530^{\circ} \mathrm{C}$ and quenched in water gave the highest value of 35.50 in hardness (HRC). The toughness property of the alloy, as indicated by Charpy impact values, is better at $530^{\circ} \mathrm{C}$ for specimen quenched in sheanut oil and least impact strength is observed in specimen quenched in water at $400^{\circ} \mathrm{C}$.

\section{LITERATURE REVIEW}

\subsection{Solution Heat Treating of Aluminum Alloys}

The purpose of solution heat treatment of aluminum is to obtain the maximum concentration of hardening solute, such as zinc, magnesium and copper, in solution by heating the alloy to a temperature in which single phase will be created. By doing so, the solute atoms that were originally part of a two-phase solid solution dissolved back into solution and create one single phase in equilibrium. Once the alloy has been held for a considerable amount of time to ensure complete solutioning and homogenous phase, it is quenched rapidly such that the solute atoms do not have enough time to precipitate out of solution. As a result, a super saturated solution now exists between the solute and aluminum matrix. The heat - treating process is best understood by studying a phase diagram and examining the temperature ranges and phase regions that are involved. These diagrams do not show the actual structures formed during the heat treatment processes, but they are a useful tool in predicting the solid state reactions that will take place at a given temperature and composition [5]. 


\subsection{Quenching}

This is the process of rapid cooling of materials to room temperature to preserve the solute in solution. The cooling rate needs to be fast enough to prevent solid - state diffusion and precipitation of the phase. The rapid quenching creates a saturated solution and allows for increased hardness and improved mechanical properties of the material. In addition, studies have shown that the highest degrees of corrosion resistance have been obtained through the maximum rates of quenching $[3,6]$.

In general terms, liquid quenching is performed in water, oil and more recently, in aqueous polymer solutions. Water and oil quenching cover the extremes in terms of cooling rates, with water being the fastest and oil being the slowest. Quenching takes place in three distinct stages, namely: Vapour blanket stage, Boiling stage and Liquid cooling stage. The vapour blanket stage begins when the hot part makes contact with the quenching medium. As the part is submerged, an unbroken blanket surrounds the piece. This blanket exists between the specimen and quenching media if the heat from the surface of the part exceeds the amount of heat needed to form the maximum vapour per unit area on the piece. This stage is characterized by a relatively slow cooling rate since the vapour of the quenching medium surrounds the part and acts as an insulator. In this particular stage, heat is removed from the part by radiation and conduction through the vapour layer. As the component cools, the vapour blanket cannot be maintained and therefore, breaks down. After this breakdown, the boiling stage immediately begins. The surface of the part now comes in direct contact with the fluid and result in violent boiling of the medium. This stage is characterized by rapid heat transfer through the heat of vaporization. Size and shape of the vapour bubbles are important in controlling the duration of this stage as well as its corresponding rate. As the part continues to cool below the boiling point of the medium, the boiling stage can no longer exist and it too break down giving way to liquid cooling stage. This stage, much like the vapour blanket stage, is also characterized by slow rates of heat transfer. Heat is dissipated from the part by movement of the quenching medium by conduction currents. The difference in temperature between the boiling point of the medium and actual temperature of the medium is the major factor influencing the rate of heat transfer in liquid quenchants.

Furthermore, viscosity of the medium at this point also affects the cooling rate since a less viscous medium will dissipate heat faster than one of high viscosity. The final stage of quenching is the most important in controlling and reducing distortion and cracking [7-8].

\subsection{Quench Factor Analysis (QFA)}

To successfully predict the metallurgical consequences of quenching, it is necessary to determine the heat transfer properties produced by the various quenching medium during the cooling. Cooling curve analysis has been considered to be the best method to obtain such information [9]. 
Quench factor analysis (QFA) has several advantages over other methods. Quench factor analysis provides a single value describing quench severity for the specific alloy being quenched. In addition, the quench factor is directly related to the hardness of the quenched part and intermediate manual interpretations are not required. So, it can be seen that QFA is highly beneficial in the quenching process [10].

The determination of the Quench Factor, $\mathrm{Q}_{1}$ begins with the calculation of a variable called the incremental quench factor $(\tau)$. This variable is calculated for each time step in cooling process using equation 1.0:

$$
T=\frac{\Delta t}{C_{T}}----------------------------1.0
$$

$\mathrm{T}=$ Incremental quench factor

$\Delta \mathrm{t}=$ Time step used in cooling curve data acquisition.

The $\mathrm{C}_{\mathrm{T}}$ function is defined below as well as the variables that help create it [9-11].

$$
C_{T}=K_{1}-K_{2} e^{\left[\frac{K_{3}-K_{4}^{2}}{R_{T}\left(K_{4}-T\right)^{2}}\right]} e^{\left(\frac{K_{5}}{R_{T}}\right)}-----------------2.0
$$

Where

$\mathrm{C}_{\mathrm{T}}=$ Critical time required to form a constant amount of a new phase or reduce the hardness by a specific amount.

$\mathrm{K}_{1}=$ Constant which equals the natural logarithm of fraction untransformed during quenching (the fraction defined by the TTP curve).

$\mathrm{K}_{2}=$ Constant related to the reciprocal of the number of nucleation sites.

$\mathrm{K}_{3}=$ Constant related to the energy required to form a nucleus.

$\mathrm{K}_{4}=$ Constant related to the Solvus temperature.

$\mathrm{K}_{5}=$ Constant related to the activation energy for diffusion

$\mathrm{R}=8.3143 \mathrm{~J} / \mathrm{k}$ mole

$\mathrm{T}=$ Absolute temperature $(\mathrm{k})$

Values for the above constant were found experimentally by Totten, Bates and Javis [7]. Table 1 illustrates these constants for four different aluminum alloys.

Table 1: Constant for various aluminum

\begin{tabular}{|l|l|l|l|l|l|l|}
\hline \multicolumn{1}{|c|}{ Alloy } & \multicolumn{1}{c|}{$\mathrm{K}_{1}$} & \multicolumn{1}{c|}{$\mathrm{K}_{2}$} & \multicolumn{1}{|c|}{$\mathrm{K}_{3}$} & \multicolumn{1}{c|}{$\mathrm{K}_{4}$} & \multicolumn{1}{c|}{$\mathrm{K}_{5}$} & $\begin{array}{c}\text { Temperature } \\
\text { Range }\left({ }^{0} \mathrm{C}\right)\end{array}$ \\
\hline $7050-\mathrm{T} 76$ & -0.00501 & $2.20 \mathrm{E}-19$ & 5190 & 850 & $1.80 \mathrm{E}+05$ & $425-150$ \\
$7057-\mathrm{T} 6$ & -0.00501 & $4.10 \mathrm{E}-13$ & 1050 & 780 & $1.40 \mathrm{E}+04$ & $425-150$ \\
$2024-\mathrm{T} 851$ & -0.00501 & $1.72 \mathrm{E}-11$ & 45 & 750 & $3.20 \mathrm{E}+04$ & $440-110$ \\
$7075-\mathrm{T} 73$ & -0.00501 & $1.37 \mathrm{E}-13$ & 1069 & 737 & $1.37 \mathrm{E}+05$ & $425-150$ \\
\hline
\end{tabular}




\section{EXPERIMENTAL METHODOLOGY}

\subsection{Materials and Equipment}

The materials and equipment used during the experiments include 6061 Aluminum alloy, Quenching medium, Melting furnace, Heat treatment furnace, Impact testing machine, Tensile testing machine, Hardness testing machine, Grinding machine, Rotary wheel polishing machine, Etching reagent, and Binocular metallurgical microscope.

Three kilogram of 6061 Aluminum alloy was obtained from the Nigerian Aluminum Extrusion Company (NIGALEX) Lagos. The chemical concentration analysis of the alloy was also obtained from the company. Table 2 shows the concentration analysis of the 6061 Aluminum alloy used.

Table 2: Chemical analysis of the 6061 aluminum

\begin{tabular}{|c|c|c|c|c|c|c|c|c|c|c|c|}
\hline Run & $\mathrm{Si}$ & $\mathrm{Fe}$ & $\mathrm{Cu}$ & $\mathrm{Mn}$ & $\mathrm{Mg}$ & $\mathrm{Zn}$ & $\mathrm{Cr}$ & $\mathrm{Ti}$ & $\mathrm{Ca}$ & $\mathrm{Sr}$ & $\mathrm{Al} \%$ \\
\hline Avg & 4.4174 & 0.6269 & 0.1438 & 2.0626 & 2.5151 & 0.6489 & 0.02172 & 0.0105 & -0.1332 & -0.0002 & 89.6875 \\
\hline
\end{tabular}

The quenching media used during the experiment were three (3): water, sheanut oil and palm kernel oil. The two quenching media, Sheanut and Kernel oil were obtained locally from Birnin Kebbi market.

Table 3: Quenching media physical properties

\begin{tabular}{|l|c|c|c|c|c|}
\hline \multicolumn{1}{|c|}{$\begin{array}{c}\text { Quenching } \\
\text { Media }\end{array}$} & $\begin{array}{c}\text { Temp } \\
\left({ }^{0} \mathrm{c}\right)\end{array}$ & $\begin{array}{c}\text { Specific } \\
\text { Gravity }\end{array}$ & $\begin{array}{c}\text { Specific } \\
\text { Heat } \\
\text { Capacity } \\
\left(\mathrm{JKg}^{-10} \mathrm{k}\right)\end{array}$ & $\begin{array}{c}\text { Density } \\
\left(\mathrm{Kg} / \mathrm{m}^{3}\right)\end{array}$ & $\begin{array}{c}\text { Viscosity } \\
\mathrm{Ns} / \mathrm{m}^{2}\end{array}$ \\
\hline Tap water & 26 & 1.002 & 4190.0 & 1000 & $0.8 \times 10^{-3}$ \\
\hline Palm kernel oil & 26 & 0.912 & 2020 & 970 & $36 \times 10^{-3}$ \\
\hline Raw G/nut oil & 26 & 0.904 & 1930 & 920 & $36 \times 10^{-3}$ \\
\hline $\begin{array}{l}\text { Engine oil [SAE } \\
\text { 20 W-50 }\end{array}$ & 26 & 0.924 & 1900 & 890 & $050 \times 10^{-3}$ \\
\hline
\end{tabular}

\subsection{Experimental Procedure}

Three kilogram of 6061 Aluminum alloy was obtained from the Nigerian Aluminum Extrusion Company (NIGALEX) Lagos. Sand moulds were prepared for casting rods of $30 \mathrm{~mm}$ diameter from the Aluminum alloy melted in an oil-fired crucible furnace. After solidification, the moulds were broken to obtain the cast rods. The cast rods were taken to the machine shop for preparation 
into tensile, impact and hardness tests' specimens. The specimens were prepared based on the ASTM standard.

The prepared 6061 Aluminum alloy samples, was quenched in three (3) different quenching medium, water, palm kernel, sheanut oil, using varying solutionizing temperatures of $530^{\circ} \mathrm{C}$, $450^{\circ} \mathrm{C}$ and $400^{\circ} \mathrm{C}$.

\subsubsection{Heating Operation}

A carbolite GLM3 model box furnace was used to heat the prepared samples to the selected solutionizing temperature of $400^{\circ} \mathrm{C}, 450^{\circ} \mathrm{C}$, and $530^{\circ} \mathrm{C}$. The samples were arranged in the furnace in such a way as to allow uniform circulation of hot air to all the specimens. Nine (9) samples were heated at every heating operation. A total of three (3) heating operations were conducted in each case.

\subsubsection{Quenching Operation}

After heating was completed, the various samples were quenched in water, shea-nut oil and palm oil baths respectively. The baths were agitated in order to increase the rate of heat transfer through the quenching process. After the completion of the quench, the samples were removed from the various mediums and sanding was done after each quench to maintain a consistent surface finish of the specimen throughout the experiments.

\subsubsection{Testing Operation}

Avery Denison T4CI/33470 model, 6705U/33458 model and 6408/33267 model machines were used to test for the tensile strength, toughness and Rockwell hardness respectively.

\subsubsection{Metallographic Examination}

The specimens for micro examination were prepared by grinding on hand grinding deck of abrasive papers of grades 240, 400, 600 and 1000. Polishing was done on a universal rotary wheels using alumina as the polishing medium. The thoroughly polished specimen was washed in warm water and swabbed with methylated spirit and dried using warm air. Etching was done in a solution of one percent (1\%) Sodium Hydroxide in water by swabbing the polished surface of the specimen with the etching reagent. A Leitz model binocular metallurgical microscope (the bench type) was used to view the micro - structural changes that took place in all the prepared samples. 


\section{EXPERIMENTAL RESULTS AND DISCUSSIONS}

\subsection{Presentation of Result}

\subsubsection{Tensile test}

The tensile test specimens were tested to fracture on a tensile testing machine. From the data generated, ultimate tensile strength, yield strength, percentage elongation and percentage reduction in area were calculated. The results are as presented in Table 4.

\subsubsection{Rockwell hardness test}

The results obtained from hardness test conducted using the Rockwell hardness test method and three indentations are presented in Figure 1.

Table 4: Tensile test results of 6061 aluminum quenched in different media

\begin{tabular}{|c|c|c|c|c|c|}
\hline $\begin{array}{c}\text { Quenching } \\
\text { Media }\end{array}$ & $\begin{array}{c}\text { Heat } \\
\text { Treatment } \\
\text { Temp. (0C) }\end{array}$ & $\begin{array}{c}\text { Solution } \\
\text { Time (Hours) }\end{array}$ & UTS N/mm ${ }^{2}$ & $\begin{array}{c}\text { Yield } \\
\text { Strength } \\
\mathrm{N} / \mathrm{mm}^{2}\end{array}$ & $\begin{array}{c}\text { Percentage } \\
\text { Elongation \% }\end{array}$ \\
\hline \multirow{3}{*}{ Water } & 450 & 2 & 85.77 & 63.12 & 7.00 \\
\hline & 450 & 2 & 87.69 & 67.73 & 6.11 \\
\hline & 530 & 2 & 109.70 & 70.89 & 4.00 \\
\hline \multirow{3}{*}{ Sheanut oil } & 450 & 2 & 78.12 & 59.63 & 6.35 \\
\hline & 450 & 2 & 86.37 & 62.73 & 6.00 \\
\hline & 530 & 2 & 88.00 & 66.72 & 3.75 \\
\hline \multirow{3}{*}{$\begin{array}{c}\text { Palm Kernel } \\
\text { Oil }\end{array}$} & 450 & 2 & 74.07 & 55.53 & 6.01 \\
\hline & 450 & 2 & 77.04 & 57.60 & 5.50 \\
\hline & 530 & 2 & 90.10 & 64.94 & 2.98 \\
\hline $\begin{array}{l}\text { Control } \\
\text { sample }\end{array}$ & - & - & 83.80 & 64.44 & 5.0 \\
\hline
\end{tabular}




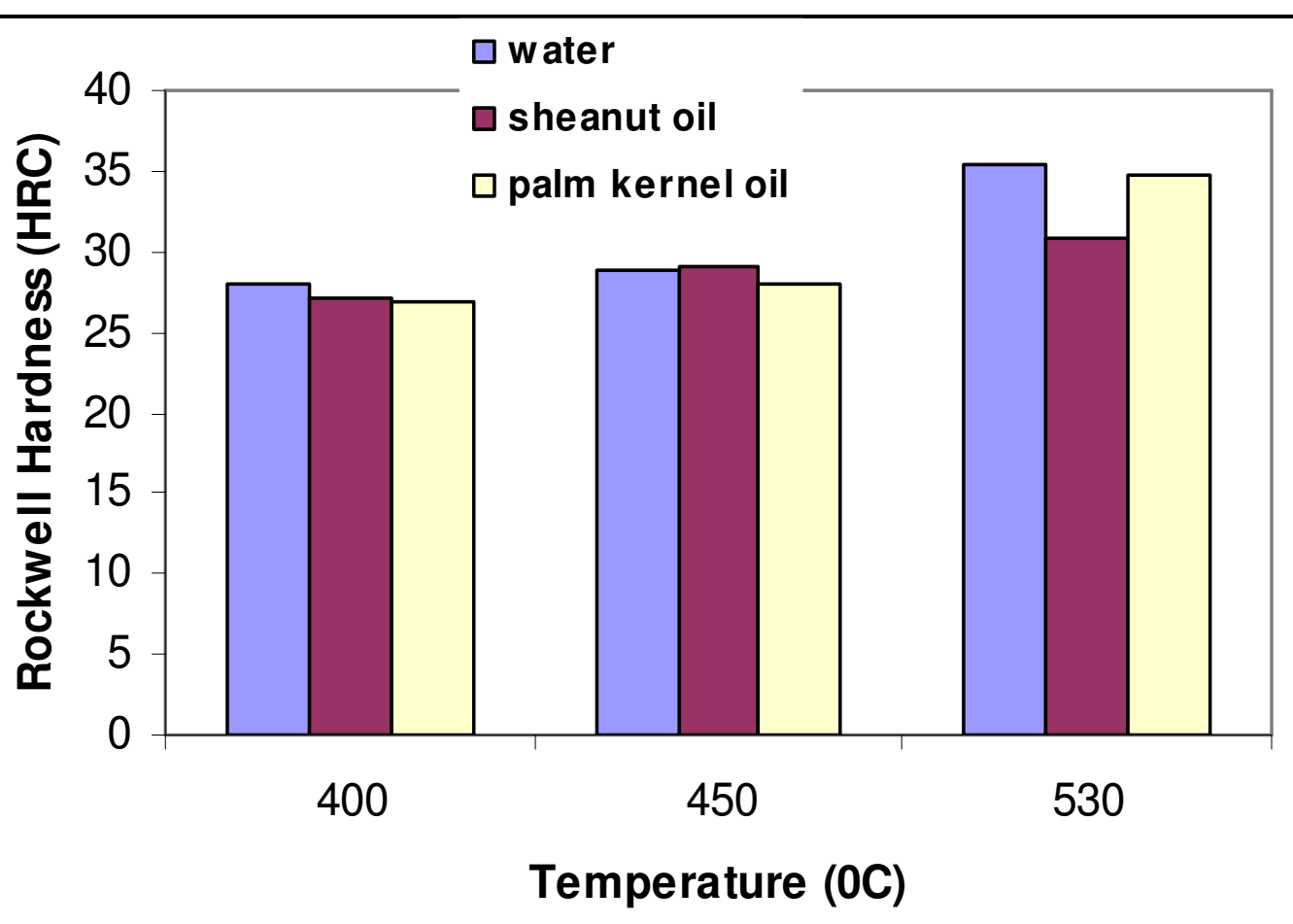

Figure 1: Effect of Temperature and Quenching Media on Rockwell Hardness of 6061 Aluminum Alloy.

\subsubsection{Impact test}

The results obtained from the V-notch Charpy test are shown in Table 5.

Table 5: Charpy impact test results for 6061 aluminum alloy quenched in different media

\begin{tabular}{|l|c|c|}
\hline \multicolumn{1}{|c|}{ Quenching Media } & Temperature $^{\mathbf{0}} \mathbf{C}$, & $\begin{array}{c}\text { Charpy Impact } \\
\text { Values(J) }\end{array}$ \\
\hline \multirow{3}{*}{ Water } & 400 & 26 \\
& 450 & 27 \\
& 530 & 60 \\
\hline \multirow{3}{*}{ Sheanut Oil } & 400 & 49.6 \\
& 450 & 50.1 \\
& 530 & 65 \\
\hline \multirow{2}{*}{ Palm Kernel Oil } & 400 & 41.2 \\
& 450 & 42.2 \\
\hline Control Sample & 530 & 41 \\
\hline
\end{tabular}




\subsubsection{Micro structural analysis}

The microphotograph of specimens quenched in the various media at $530^{\circ} \mathrm{C}$ is presented in Plate I. Plate II presented specimen quenched at $450^{\circ} \mathrm{C}$ and Plate III represent specimens quenched at $400^{\circ} \mathrm{C}$. A,B and $\mathrm{C}$ in all cases represent microphotographs for specimens quenched in water, Palm kernel and Sheanut oil respectively.

\subsection{Discussion of Results}

\subsubsection{Tensile test}

The results of the tensile strength test are shown in Table 4 when the samples were heated to $530^{\circ} \mathrm{C}, 450^{\circ} \mathrm{C}$, and $400^{\circ} \mathrm{C}$. The highest ultimate tensile strength values were obtained in samples quenched in water, sheanut oil, and palm oil at $530^{\circ} \mathrm{C}$. The corresponding ultimate tensile strength was $109.0 \mathrm{~N} / \mathrm{mm}^{2}, 88.0 \mathrm{~N} / \mathrm{mm}^{2}$ and $90.1 \mathrm{~N} / \mathrm{mm}^{2}$ respectively. Similarly the yield strength obtained was $70.89 \mathrm{~N} / \mathrm{mm}^{2}, 66.72 \mathrm{~N} / \mathrm{mm}^{2}, 64.94 \mathrm{~N} / \mathrm{mm}^{2}$ respectively. The values for the control system are ultimate tensile strength $83.8 \mathrm{~N} / \mathrm{mm}^{2}$ and yield strength of $64.44 \mathrm{~N} / \mathrm{mm}^{2}$. Samples quenched in sheanut oil and palm kernel oil at $530^{\circ} \mathrm{C}$ showed a marginal increase in reduced strengths (ultimate and yield strength) when compared to the values for the control sample. However, the highest ultimate tensile strength of $109.7 \mathrm{~N} / \mathrm{mm}^{2}$ was obtained with sample heated to $530^{\circ} \mathrm{C}$ and quenched in water. The values of tensile strength are influenced by the microstructure of the aluminum alloy sample, which are controlled by the quenchant's cooling rate. In contrast to the behaviour of the control sample specimen, specimens quenched in sheanut and water exhibited high values tensile strength at $530^{\circ} \mathrm{C}$ at the same time maintaining low ductility. This show that the high strength produced is due to the effectiveness of the quenchants and their characteristics as shown.

\subsubsection{Rockwell hardness}

The results are presented also in graphical form (Figure. 1). The homogenous distribution of the fine precipitate of copper, in Aluminum matrix is largely responsible for the hardness of the quenched aluminum alloy. The hardness of the aluminum alloy specimens quenched in water, sheanut and palm kernel at a solutionizing temperature of $530^{\circ} \mathrm{C}$ increased. This is as a result of the fact that quenched alloy is no longer in "equilibrium" which precipitate silicon. The hardness of the quenched aluminum alloy increased significantly as compared to the control sample.

\subsubsection{Impact test (Charpy)}

The results for the impact test are shown in Table 5. The treated samples in all cases show a remarkable increase in the toughness when compared to a value of 20.50 Joules for the control 
sample. However, the sample heated at $530^{\circ} \mathrm{C}$ and quenched in palm kernel oil has the highest value of 65 Joules.

\subsubsection{Microstructure examination}

The result of microstructural examination of the specimens shows that the specimens quenched in water, Sheanut and palm kernel oil at $530^{\circ} \mathrm{C}$ show higher values of ultimate tensile strength as shown in Table 4. This is associated with fine precipitates, which impact improved strength as compared to other specimens, which have a little coarse dispersion of precipitates. The changes in structure of the specimen are associated with the temperature of solutioning and the cooling rate of the quenching medium.

The very high rate of heat extraction experienced by the specimen quenched in water after solution treatment at $530^{\circ} \mathrm{C}$ could be said to be responsible for the fine microstructure observed in plate 1A. The precipitates are also uniformly distributed in Aluminum matrix. Generally, hardness and strength increases as grain size decreases. Both properties are proportional to the reciprocal of the square root of the average grain diameter. The relatively slower cooling rate is responsible for the formation of platelet-like precipitates in specimen quenched in sheanut oil. To a lesser extent, (compared to water quenching) the presence of spherodised grains is observed in specimen quenched in palm kernel oil.

\section{CONCLUSION}

The study on the effect of various quenching media (water, sheanut oil and palm kernel oil) on rapidly quenched 6061 aluminum alloy was conducted and attempt were made to relate mechanical properties to microstructure. As a result of this investigation, the following conclusions were made regarding the effect of several quenching media on the alloy.

Increase solution treatment temperature was found in improved soluble precipitates in the alloy, and the heat extraction capacity of the quenching medium also contributed to the formation of fine precipitates. Water among the quenching media proved to have the highest cooling rate, followed by Sheanut oil. Improvements in properties may be correlated with a more refined metallurgical structure.

High values of strength, hardness and notch strength were typically associated with fine precipitate distribution.

Careful choice of cooling media with appropriate choice of heat treatment procedure and parameters were effective in producing desired mechanical properties. 


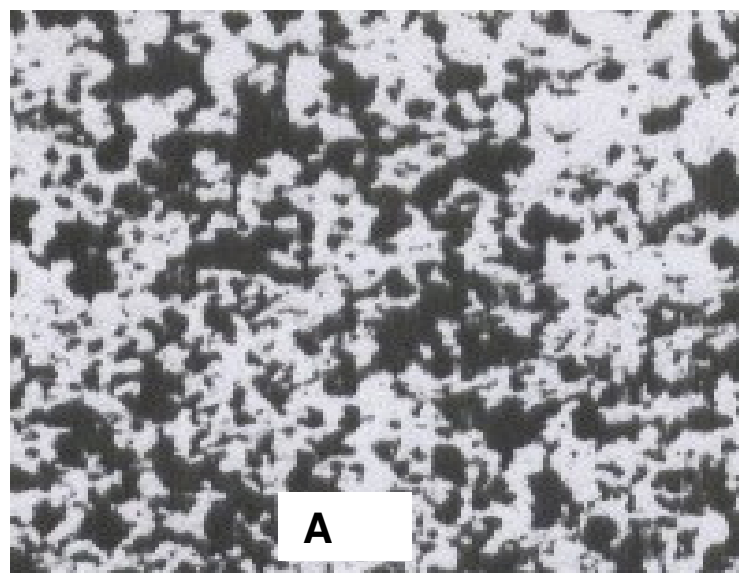

Plate 1A: Aluminum 6061 quenched in water at $530^{\circ} \mathrm{C}$. Precipitates formed by $\mathrm{Si}$ $\mathrm{Mn}$ and $\mathrm{Mg}$ spherodised in Al-matrix (mag x 300)

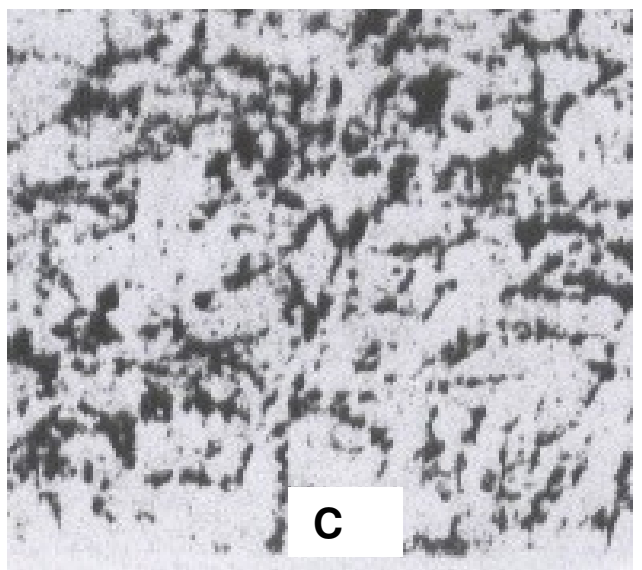

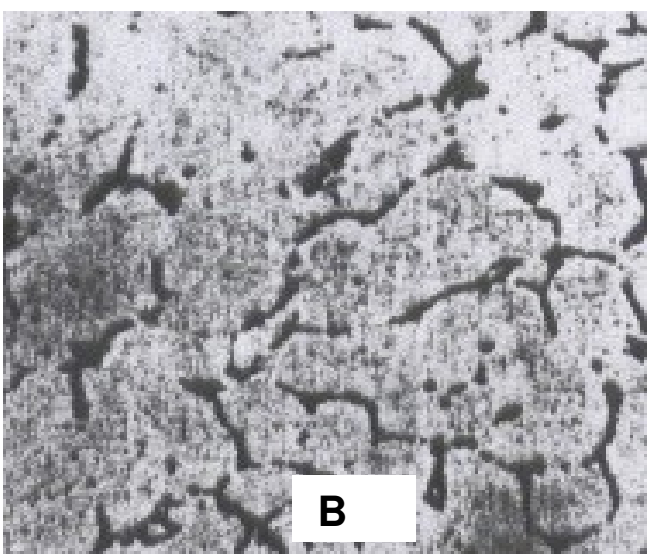

Plate 1B: Aluminum 6061 quenched in palm kernel oil at $530^{\circ} \mathrm{C}$, plate lets of precipitates sharing partial spherodisation (mag x 300)

Plate 1C: Aluminum 6061 quenched in Sheanut oil at $530^{\circ} \mathrm{C}$ showing growth of precipitates leading to sub grains of concentrated precipitates (mag x 300)

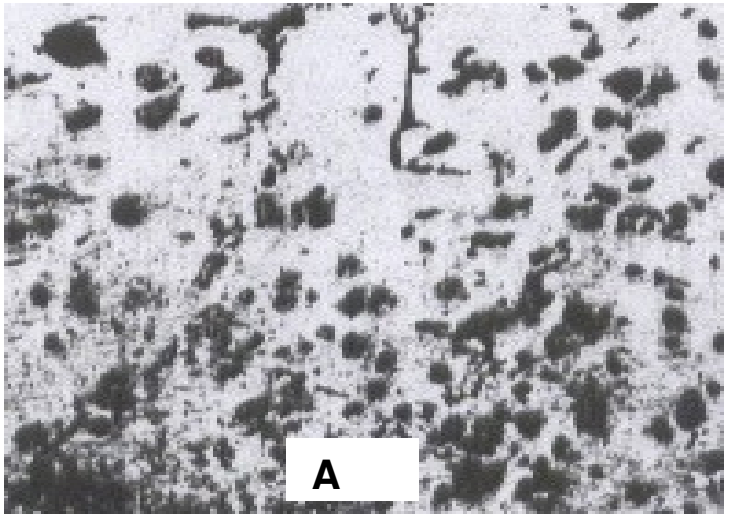

Plate 2A: In 6061 quenched in water at $450^{\circ} \mathrm{C}$ less spherodisation of precipitates (mag x 300)

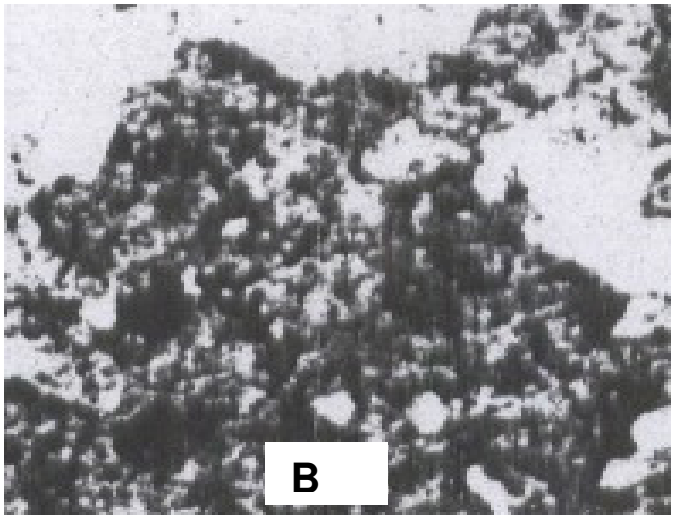

Plate 2B: Aluminum 6061 quenched in sheanut oil at $450^{\circ} \mathrm{C}$ more spherodisation of precipitates as compared to plate IIA (mag x 300) 

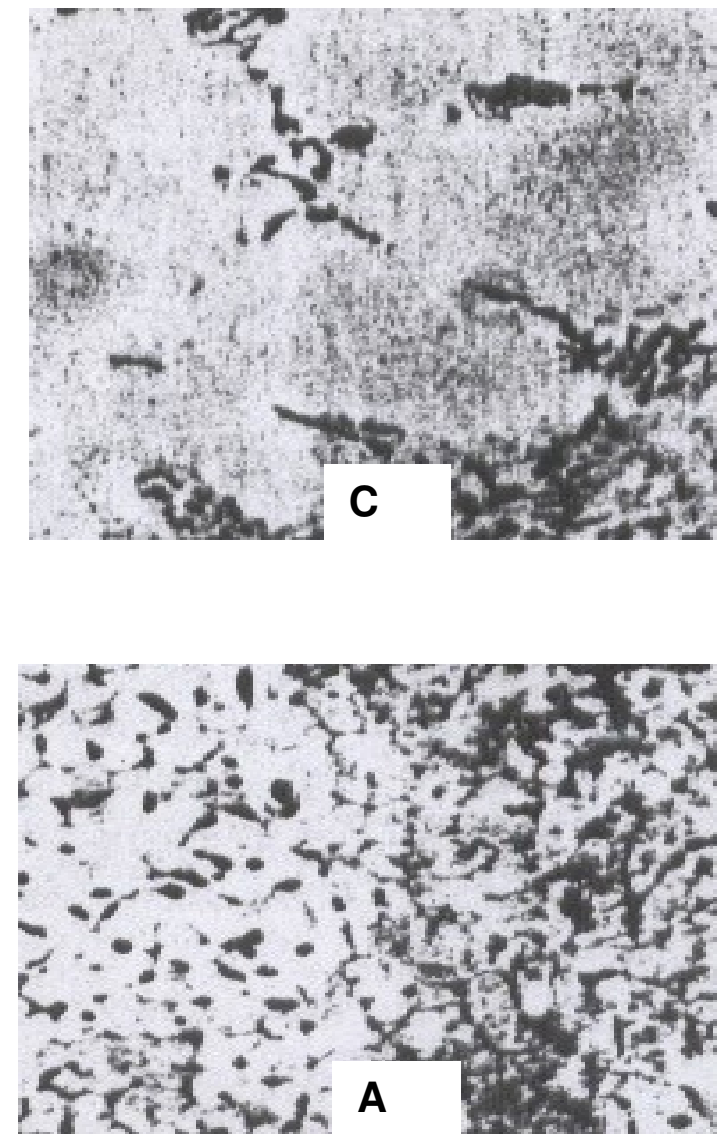

Plate 3A: Aluminum 6061 quenched in water at $400^{\circ} \mathrm{C}(\operatorname{mag} \times 300)$

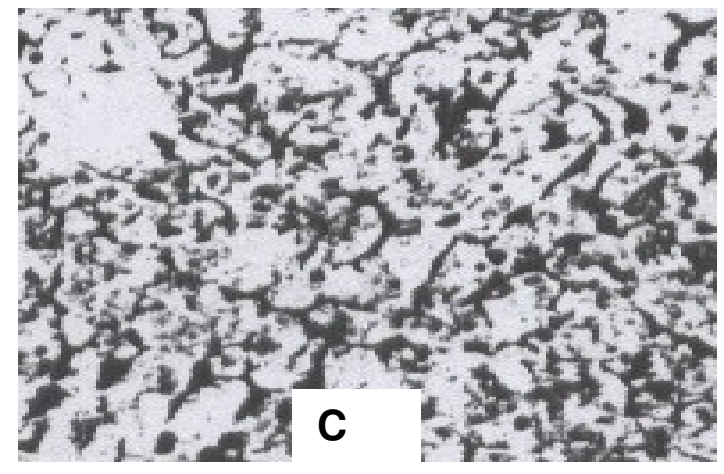

Plate 3C: Aluminum 6061 quenched in Palm kernel oil at $400^{\circ} \mathrm{C}$ (mag 300)
Plate 2C: Aluminum 6061 quenched in palm Kernel oil at $430^{\circ} \mathrm{C}$ shows abnormal Segregation of secondary phase (mag x 300)

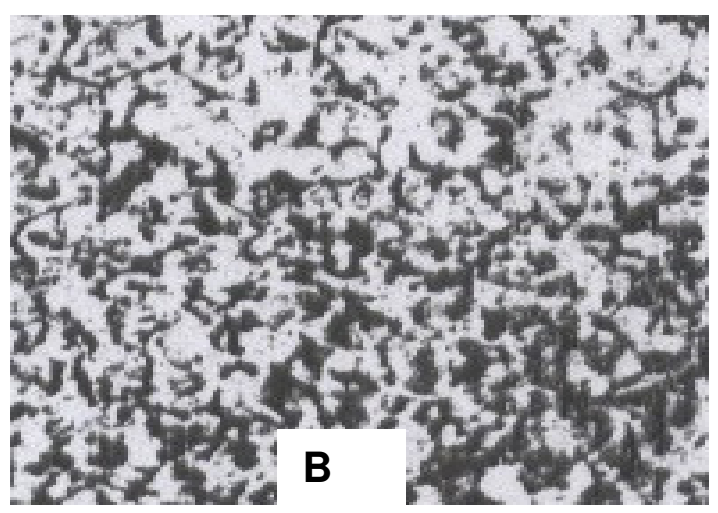

Plate 3B: Aluminum quenched in Sheanut oil at $400^{\circ} \mathrm{C}(\operatorname{mag} \times 300)$ 


\section{REFERENCES}

[1] Rajan T. V. Sharma, C. P., Ashok Sharma, 1988, Heat treatment Principles Techniques, Rajkarnal Electric Press. India. Page 142-149.

[2] Davis J. R., 1993, Aluminum and Aluminum Alloys, in ASM Specially Handbook, ASM International, Metal Park, Ohio.

[3] Callister, W. D., 1997, Material Science and Engineering, John Wiley and Sons, New York.

[4] Boyer,H. E., 1998, Quenching and Distortion Control, ASM International, Metal Park, Ohio.

[5] Avner, Sidney H., 1982, Introduction to Physical Metallurgy, Mc Graw-Hill International Book Company, Tokyo.

[6] Rollanson E. C., 1998, Metallurgy for Engineers, Edward Arnold Ltd., London.

[7] Bates C. E., Totten G. T., and Webster G. M., 1998, "cooling curve and quench factor characterization of 2024 and 7075 Aluminum Bar stock quenched in type 1. Polymer." Quenchant, Vol. 29, No 1 -3.

[8] Hasson J.., 1992, "Quenchants: Yesterday, Today and Tomorrow", Proceedings of the First International Conference on Quenching, Chicago Illinois.

[9] Bates, C. E., Javis L. M., and Totten G. E., 1986, "Use of quenching factor for predicting the properties of polymer quenching media." Metal Science and Heat Treatment, Vol. 38, No. 5 6, pp. $13-17$.

[10] Stanley J. T., 1987, Quench factor Analysis of Aluminum alloys, The Institute of Metals London, pp. 923 - 934.

[11] Mackenzie, D. S., and Totten G. E., 2000, "Aluminum Quenching Technology- A Review." Materials Science Forum, Vol. 331, pp. 589 - 594. 